\title{
THE NOVEMBER MEETING IN LOS ANGELES
}

The five hundred thirty-ninth meeting of the American Mathematical Society was held at the University of California in Los Angeles on Friday and Saturday, November 15 and 16, 1957. There were 216 registrants, including 182 members of the Society.

By invitation of the Committee to Select Hour Speakers for Far Western Sectional Meetings, a Symposium on Game Theory was held on Friday. The program committee for the Symposium consisted of Professors David Blackwell, Chairman, H. F. Bohnenblust, Samuel Karlin, and Harold Kuhn. For the first session of the Symposium, Professor Blackwell presided, and half-hour talks were presented as follows: Survey of continuous games on the unit square and outstanding problems, Professor Samuel Karlin, Stanford University; Infinitely repetitive games, Dr. Philip Wolfe, RAND Corporation; Multimove infinite games, Dr. Melvin Dresher, RAND Corporation; On multimove games, Professor Rodrigo Restrepo, University of British Columbia; Some experiments on games on electronic computing machines, Dr. Stanislaw Ulam, Los Alamos Scientific Laboratory.

The second session of the Symposium was presided over by Dr. Wolfe, the talks being as follows: $A$ survey of extensive games, Professor Harold Kuhn, Bryn Mawr College; Markov learning models for game situations, Professor Patrick Suppes, Stanford University. Chairman for the third session was Dr. Olaf Helmer, and the speakers were as follows: Games with vector outcomes, Dr. Lloyd Shapeley, RAND Corporation; Simple games and finite solutions, Dr. Herbert Gurk, Radio Corporation of America; Descriptive theory of simple games, Dr. John Isbell, University of Washington; $A$ cooperative $n$-person bargaining game, Professor David Gale, RAND Corporation.

By invitation of the Committee to Select Hour Speakers for Far Western Sectional Meetings, Professor Harold Levine of Stanford University addressed the Society on Saturday, on the topic Recent developments in the theory of wave motion. He was introduced by Professor Arthur Erdelyi.

The sessions for contributed papers were presided over by Professors Charles Loewner, J. D. Swift, and Lida Barrett. Mr. Iwao Sugai was introduced by Professor J. W. Green and Mrs. Emma Lehmer by Professor V. L. Klee, Jr.

Abstracts of the contributed papers will be published in the February and April issues of the Notices of the American Mathematical Society.

V. L. KLEE, JR., Associate Secretary 